\title{
Didáctica integrada de lenguas : una propuesta de activadades
}

Jordi Cicres, Maria-Dolors de Ribot y Sílvia Llach

\section{(2) OpenEdition \\ Journals}

Edición electrónica

URL: http://journals.openedition.org/trema/3202

DOI: $10.4000 /$ trema.3202

ISSN: 2107-0997

\section{Editor}

Faculté d'Éducation de l'université de Montpellier

\section{Edición impresa}

Fecha de publicación: 1 noviembre 2014

Paginación: 66 - 75

ISSN: 1167-315X

\section{Referencia electrónica}

Jordi Cicres, Maria-Dolors de Ribot et Sílvia Llach, «Didáctica integrada de lenguas : una propuesta de activadades », Tréma [En ligne], 42 | 2014, mis en ligne le 16 juin 2015, consulté le 03 mai 2019. URL : http://journals.openedition.org/trema/3202 ; DOI : 10.4000/trema.3202

Este documento fue generado automáticamente el 3 mayo 2019. 


\title{
Didáctica integrada de lenguas : una propuesta de activadades
}

\author{
Jordi Cicres, Maria-Dolors de Ribot y Sílvia Llach
}

\section{Introducción}

1 El contexto actual de globalización económica y cultural, junto con la extensión de las tecnologías de la información y la comunicación, conlleva nuevas necesidades formativas en el ámbito lingüístico. Los escolares viven en un mundo plurilingüe y pluricultural. Por ejemplo, en Cataluña, en la escuela conviven dos lenguas cooficiales (catalán y castellano) junto con otras lenguas de estudio curricular (inglés, y en menor medida francés) y decenas de primeras lenguas de los alumnos con ascendencia extranjera. Pero dentro y fuera de la escuela, los niños están en contacto cotidiano con multitud de lenguas: navegando por internet, jugando a videojuegos, viendo la televisión, escuchando a los vecinos, etc. De acuerdo con Lasagabaster (1998), se puede decir que en Cataluña se dan dos tipos de multilingüismo: el multilingüismo individual, que consiste en la presencia de diversas lenguas en la vida cotidiana de los individuos (por ejemplo, sería el caso de un inmigrante que reside en una comunidad bilingüe); y el multilingüismo de la escuela, que se puede definir como la presencia de más de dos lenguas en el currículum escolar.

2 La escuela debe adaptarse a esta nueva realidad, y debe preparar a los alumnos para un mundo en el que la comunicación (multilingüe) va a desempeñar un papel cada vez más relevante. El reto de formar lingüísticamente a los niños trasciende el rol tradicional de enseñar la gramática de cada una de las lenguas estudiadas.

3 Es necesario utilizar un enfoque más global que permita aprovechar las sinergias que puede aportar una enseñanza lingüística más globalizada. Por ejemplo, como señalan Ferrer y Rodríguez (2010), es necesario:

1. encontrar un enfoque teórico y metodológico compartido en la docencia de todas las lenguas escolares, que implica no solo una terminología gramatical común, sino también una concepción lingüística compartida; y 
2. definir un eje pedagógico que dé coherencia al conjunto del aprendizaje lingüístico, ya sea con una actuación coordinada en el aprendizaje del código (de modo que se puedan evitar repeticiones de explicaciones y ejercicios que son claramente equivalentes en las lenguas de estudio, como las nociones de las categorías gramaticales o la tipología textual) como con el trabajo en las distintas habilidades comunicativas.

4 En este artículo nos proponemos tres objetivos: en primer lugar, analizar los requerimientos legales que marca el currículum de la educación primaria de Cataluña; en segundo lugar, fundamentar teóricamente las ventajas de la programación integrada de las lenguas escolares; y finalmente, aportar ejemplos de actividades concretas que constituyan modelos válidos para la programación integrada entre las tres lenguas escolares de Cataluña (catalán, castellano e inglés u otra lengua extranjera).

\section{El marco curricular}

5 En Cataluña, el currículum escolar para la etapa educativa de los 6 a los 12 años (educación primaria) establece como objetivo principal en el ámbito de la enseñanza lingüística lo siguiente (pág. 30-31):

«La finalitat de l'ensenyament de les llengües és el progressiu domini de llengües, essencial en la vivència de la cultura i l'obertura al món i un dels factors que contribueix més plenament a la identitat social i personal. [...] Això vol dir que les nenes i els nens, en acabar l'etapa:

1. han de dominar el català, llengua vehicular, de cohesió i d'aprenentatge;

2. també han de dominar el castellà;

3. han de conèixer una o dues llengües estrangeres per tal d'esdevenir usuaris $i$ aprenents capaços de comunicar-se i accedir al coneixement en un entorn plurilingüe i pluricultural;

4. han de comprendre missatges escrits bàsics i establir relacions entre llengües romàniques;

5. han de tenir una actitud oberta, respectar les llengües i cultures presents en l'entorn on viuen i interessar-s'hi, i també ho han de fer respecte d'altres de més llunyanes, de les quals poden aprendre i enriquir-se personalment, malgrat no les aprenguin mai [...].»

6 El currículum también concreta la necesidad de trabajar las lenguas de modo integrado (pág. $36-37$ ):

«Atesa la realitat social, lingüística i cultural de la nostra societat, cal un ensenyament integrat de les llengües que coordini els continguts que s'aprenen i les metodologies en les diferents situacions d'aula, a fi que les nenes i els nens avancin cap a l'assoliment d'una competència plurilingüe i intercultural.»

7 Por supuesto, un currículum no puede establecer ni metodologías ni actividades concretas que permitan lograr objetivos generales, sino que debe limitarse a señalar las líneas maestras. Sin embargo, ¿está teóricamente fundada la conveniencia del tratamiento integrado de las lenguas?, y ¿con qué actividades concretas se puede hacer?

\section{El tratamiento integrado de los lenguas}

8 La conveniencia de tratar las lenguas curriculares no como una suma de lenguas sino como un ejercicio de integración, en el sentido de hacer una programación conjunta (lo que implica un acuerdo de todos los sujetos implicados en la transmisión de contenidos, actitudes y valores lingüísticos) se empezó a teorizar y llevar a la práctica en la década de 1970, con los trabajos paralelos de Hawkins (1974) y Roulet (1980), entre otros. El objetivo 
de esta línea de investigación es facilitar el aprendizaje lingüístico escolar en un contexto en el que convivían distintas concepciones lingüísticas (estructuralistas, conductistas, normativistas), objetivos de aprendizaje y metodologías (propuestas didácticas, evaluación) que causaban confusión entre los escolares. De este modo, se pretende, por un lado, aprovechar los conocimientos lingüísticos profundos de la L1 para aprender cualquier L2 (Cummins, 1979); y por el otro, facilitar la reflexión metalingüística estableciendo puentes entre todas las lenguas escolares. Esta reflexión metalingüística pone de manifiesto que una sola capacidad humana puede generar distintas concreciones, y además cruza y flexibiliza las representaciones sobre las diversas lenguas que tiene el aprendiz (Guasch, 2008). Así pues, en los contextos plurilingües, es aconsejable integrar los aprendizajes de la lengua primera y de las adicionales, porque los conocimientos sobre la lengua primera ayudan a los aprendices a comprender la organización del lenguaje y las similitudes y diferencias entre lenguas (Dolz, Gagnon \& Mosquera, 2009; Simard, 1997). Así, pues, la didáctica integrada de las lenguas es un tipo de aproximación plural cuyas finalidades son, en primer lugar, ayudar a establecer relaciones entre un número definido de lenguas, a partir de la influencia que puede ejercer la lengua primera para facilitar el aprendizaje de las otras lenguas, y/o, en segundo lugar, optimizar las relaciones entre diversas lenguas y sus aprendizajes para conseguir una competencia plurilingüe (Marep, 2008).

Sin embargo, este planteamiento no impide que continúen espacios específicos para cada una de las lenguas, destinados a tratar los aspectos gramaticales y ortográficos idiosincráticos, pero debe existir un gran espacio común en el que se reflexione sobre aspectos generales del lenguaje y de la comunicación (aspectos gramaticales, tipología textual, literatura, cultura) y se contrasten las lenguas de aprendizaje.

11 Más concretamente, parece obvio que en el tratamiento de las distintas lenguas debería haber un programa coordinado y una terminología unificada, así como la misma concepción teórica y pedagógica de la didáctica de las lenguas (que incluya un sistema de evaluación único). Además, los programas de intercomprensión entre lenguas de la misma familia lingüística (como Euromania, diseñada específicamente para escolares, o EuRom5 y EuroComRom, para adultos) ofrecen herramientas muy útiles para trabajar las habilidades comprensivas de las lenguas y, a la vez, profundizar en sus estructuras lingüísticas, especialmente en el léxico, la morfología y las estructuras sintácticas (Chardenet, 2006).

12 Finalmente, no hay que olvidar las posibilidades que ofrecen los enfoques del Tratamiento Integrado de Lenguas y Contenidos o todo el trabajo relacionado con las actitudes y la reflexión metalingüística (Noguerol, 2004).

\section{Propuesta de actividades}

13 Con el objetivo de proponer actividades concretas que sirvan como ejemplo para la programación integrada de las lenguas (en el caso de Cataluña, el catalán, el castellano y una lengua extranjera, habitualmente el inglés, aunque en algunas ocasiones minoritarias pueda ser el francés), aportamos el diseño de una actividad específica para tratar de forma integrada un aspecto concreto de fonética y fonología, otro de morfología, uno de sintaxis, y un último de pragmática. Las actividades se presentan de forma esquemática 
para facilitar su implementación y adaptación a las necesidades particulares de cada enseñanza.

\section{1. Fonética y fonología}

Las actividades para trabajar integradamente algunos aspectos fonemáticos de las tres lenguas están pensadas para ciclo inicial (6-8 años). Al final de las actividades, los alumnos tendrán que haber descubierto que hay sonidos consonánticos compartidos y sonidos consonánticos no compartidos entre tres lenguas: catalán, castellano e inglés. Por tanto, el objetivo principal es ayudar a desarrollar la conciencia metalingüística. La extensión de este objetivo a un marco comunicativo más general conlleva que el alumno también reflexione sobre las consecuencias de los usos de un sonido u otro en los actos comunicativos.

15 La actividad parte de la existencia de sonidos consonánticos compartidos y diferentes entre las tres lenguas. Los sonidos que se pueden utilizar tienen carácter fonemático y son los que figuran en el cuadro siguiente:

\begin{tabular}{|c|c|c|c|}
\hline & catalán & castellano & inglés \\
\hline$/ \mathrm{t} /$ & dental & dental & alveolar aspirado \\
\hline$/ /$ & & interdental & interdental \\
\hline$/ \mathrm{z} /$ & alveolar & & alveolar \\
\hline$/ \mathrm{J} /$ & prepalatal & & prepalatal \\
\hline$/ 3 /$ & prepalatal & & prepalatal \\
\hline$/ \mathrm{x} /$ & & velar & glotal \\
\hline$/ \mathrm{h} /$ & & & aproximante postalveolar \\
\hline$/ \mathrm{r} /$ & trill/tap & trill/tap & \\
\hline
\end{tabular}

16 A) La primera actividad consiste en la escucha de pseudopalabras. El maestro pronunciará (o tendrá grabadas) distintas pseudopalabras que contienen algún sonido específico de la lengua catalana, castellana o inglesa. Los niños deben estar agrupados en pequeños grupos heterogéneos y decidir a qué lengua «suena» cada pseudopalabra. Se puede convertir en un juego y ganar puntos, si se desea. Es importante que cada grupo verbalice por qué ha decidido que una pseudopalabra suena más cercana a una lengua que a otra, y que busquen ejemplos de palabras existentes en tal lengua para demostrarlo.

B) La segunda actividad consiste en escuchar pares de palabras. Un par consiste en dos pronunciaciones distintas de una palabra, una de las cuales es correcta y la otra utiliza un sonido que no pertenece a esa lengua (por ejemplo, $\left.{ }^{[l} \mathrm{pi}\right]$ vs. $\left[{ }^{\mathrm{l}} \mathrm{p}^{\mathrm{h}} \mathrm{i}\right]$ "pino" para el catalán; [ $\theta \mathrm{a}^{\mathrm{l}}$ pato] vs. [Jalpato] "zapato" para el castellano y $\left[{ }^{1} \mathrm{JO} \mathrm{O}^{\mathrm{Z}} \mathrm{z}\right] \mathrm{vs.}$. [ $\left.{ }^{1} \mathrm{rO}^{\circ} \mathrm{z}\right]$ para el inglés). Esta actividad también se puede hacer con frases, porque puede ayudar entender en qué consiste lo que coloquialmente se denomina "tener acento".

C) La tercera actividad consiste en la escucha de muchas palabras mezcladas de las tres lenguas, que empiecen todas por el sonido que se quiera estudiar. En el suelo del aula habrá imágenes correspondientes a las palabras, que se deberán colgar en un mural. En este mural habrá un símbolo para cada lengua y unos espacios destinados a grupos de 
sonidos, sin especificar. Al final, deberán ser capaces de comparar los sonidos parecidos o equivalentes en las tres lenguas.

\section{2. Morfología}

19 La actividad de morfología se centra en el trabajo con los prefijos. Partimos de un cuento de Gianni Rodari (en distintas lenguas, incluyendo como mínimo las tres lenguas curriculares, pero idealmente se pueden ampliar a otras lenguas románicas). Es adecuada para el ciclo medio (8-10 años).

\begin{tabular}{|c|c|c|c|c|}
\hline Catalán & Castellano & Inglés & Gallego & Italiano \\
\hline $\begin{array}{l}\text { [...] També } \\
\text { tenim el } \\
\text { "descanó". } \\
\text { - Brrr, quina } \\
\text { por! } \\
\text { - I ara! El } \\
\text { "descanó" és } \\
\text { el contrari del } \\
\text { canó i serveix } \\
\text { per a desfer les } \\
\text { guerres. } \\
\text { - I com } \\
\text { funciona ? } \\
\text { - És facilissim, } \\
\text { fins un nen el } \\
\text { pot fer anar. Si } \\
\text { hi ha guerra, } \\
\text { toquem la } \\
\text { destrompeta, } \\
\text { disparem el } \\
\text { descanó i ja } \\
\text { tenim la guerra } \\
\text { desfeta. }\end{array}$ & $\begin{array}{l}\text { [...] Luego } \\
\text { tenemos el } \\
\text { "descañón". } \\
\text { - ¡ Brrr, qué } \\
\text { miedo! } \\
\text { - ¡ Qué va ! El } \\
\text { "descañón" es } \\
\text { lo contrario al } \\
\text { cañón, y sirve } \\
\text { para deshacer } \\
\text { la guerra. } \\
\text { - ¿Y cómo } \\
\text { funciona? } \\
\text { - Es } \\
\text { sencillísimo; } \\
\text { puede } \\
\text { manejarlo } \\
\text { incluso un niño. } \\
\text { Si hay guerra, } \\
\text { tocamos la } \\
\text { destrompeta, } \\
\text { disparamos el } \\
\text { descañón y la } \\
\text { guerra queda } \\
\text { deshecha } \\
\text { rápidamente. }\end{array}$ & $\begin{array}{l}\text { [...] We also } \\
\text { have the } \\
\text { "discannon". } \\
\text { - Oh dear, I'm } \\
\text { scared! } \\
\text { - No way! The } \\
\text { "discannon" is } \\
\text { the contrary of } \\
\text { the cannon, and } \\
\text { it's used to } \\
\text { undo wars. } \\
\text { - And how } \\
\text { does it work? } \\
\text { - It's easy, even } \\
\text { a kid could } \\
\text { make it work. If } \\
\text { there's a war, } \\
\text { we play the } \\
\text { distrumpet, fire } \\
\text { the discannon } \\
\text { and there you } \\
\text { go! The war is } \\
\text { undone. }\end{array}$ & $\begin{array}{l}\text { [...] Despois } \\
\text { tamés temos o } \\
\text { descanón. } \\
\text { - Ai, que medo. } \\
\text { - Todo o } \\
\text { contrario. O } \\
\text { descanón é o } \\
\text { contrario de } \\
\text { canón, e serve } \\
\text { para desfacer a } \\
\text { guerra. } \\
\text {-E como } \\
\text { traballa ? } \\
\text {-É facilísimo, } \\
\text { mesmo un } \\
\text { cativo pode } \\
\text { manexalo. Se } \\
\text { hai guerra, } \\
\text { tocamos a } \\
\text { descorneta, } \\
\text { disparamos o } \\
\text { descanón e a } \\
\text { guerra desfaise } \\
\text { decontado. }\end{array}$ & $\begin{array}{l}\text { [...] Poi } \\
\text { abbiamo lo } \\
\text { "scannone". } \\
\text { - Brrr, che } \\
\text { paura. } \\
\text { - Tutt'altro. Lo } \\
\text { "scannone è il } \\
\text { contrario del } \\
\text { cannone, e } \\
\text { serve per } \\
\text { disfere la } \\
\text { guerra. } \\
\text { - E come } \\
\text { funciona? } \\
\text { - È facilissimo, } \\
\text { può } \\
\text { adoperarlo, può } \\
\text { adoperarlo } \\
\text { anche un } \\
\text { bambino. Se c'è } \\
\text { la guerra, } \\
\text { suoniamo la } \\
\text { stromba, } \\
\text { spariamo lo } \\
\text { scannone e la } \\
\text { guerra è súbito } \\
\text { disfatta. }\end{array}$ \\
\hline
\end{tabular}

20 El objetivo es que los alumnos descubran los procesos morfológicos de prefijación. La posibilidad de trabajarlos mediante una obra literaria y con varias lenguas a la vez debe permitir jugar con la lengua inventando palabras (e historias, por lo menos en las lenguas que mejor dominan) con otros prefijos.

21 La actividad propuesta tiene un doble objetivo:

1. Estudiar el significado de un grupo de prefijos en las lenguas escolares, empezando por el des-, pero que fácilmente se puede aprovechar para explicar el proceso de prefijación y de formación de nuevas palabras. Puede ser interesante, también, comprobar qué palabras prefijadas aparecen en los diccionarios y cuáles no.

2. Además de las lenguas del currículum, creemos importante que los escolares adquieran estrategias de reflexión metalingüística con otras lenguas de la misma familia lingüística. En este sentido, un buen ejercicio consiste en trabajar conjuntamente con varias lenguas romances (hemos adjuntado en la tabla anterior ejemplos del fragmento de Rodari en otras lenguas además del catalán, castellano e inglés).

Adicionalmente, los alumnos notarán que el inglés utiliza dos prefijos distintos: dis- y un-; el primero se utiliza en palabras con raíz románica, mientras que el segundo en palabras con origen germánico. 

literal palabra por palabra, por un lado, y de la comparación entre las tres frases, por el otro, deben descubrir que la lengua inglesa necesita la presencia del sujeto gramatical, mientras que el catalán y el castellano, como lenguas de sujeto nulo, no tienen este requerimiento (Jaeggli \& Safir, 1989). De esta forma, a partir de la comparación de frases reales o pseudoreales, serán capaces de formular hipótesis con validez general para aspectos estructurales, concretamente sintácticos, de cada una de las tres lenguas implicadas. Según Milián (2005) y Ruiz (2008), la efectividad de este tipo de aprendizaje se basa en el proceso que implica para los aprendices: partir de situaciones comunicativas, descubrir los problemas y hablar, discutir, investigar sobre los mismos para aprender, para extrapolar estos aprendizajes a situaciones futuras.

\section{4. Pragmática}

30 La actividad pragmática es apropiada para alumnos a partir del segundo ciclo (de 8 a 12 años), y se centra en las formas personales de tratamiento, que presentan peculiaridades interesantes en las lenguas de estudio. 
31 En primer lugar, en la actualidad el catalán central utiliza básicamente dos formas: tu y vostè. La primera se utiliza en contextos en los que existe confianza entre los interlocutores o bien la usa un interlocutor que se sitúa en un plano social superior (de más edad, por ejemplo) hacia su interlocutor que se encuentra en un plano social inferior. El vostè, por el contrario, se utiliza entre interlocutores que quieren respetar ciertas distancias en el tratamiento (por ejemplo, en los contextos más formales). En algunos dialectos del catalán (y también, aunque de forma casi residual en el dialecto central) la forma vós es aún viva, y se utiliza sobre todo para dirigirse a personas mayores. Es interesante conocer que en catalán el uso del vostè se inició en el siglo XVI, por lo que sería anacrónico utilizarlo en textos literarios o cinematográficos en los que la acción transcurre antes de esta fecha.

El castellano tiene también las tres formas equivalentes al catalán (tú, usted y vos), aunque sus usos difieren dialectalmente: en el castellano peninsular, se utiliza tú y usted para el trato informal y formal respectivamente, mientras que en buena parte de los dialectos americanos el uso del vos sustituye el tú.

33 Finalmente, el inglés solo tiene un pronombre para dirigirse a un interlocutor (you), independientemente del grado de formalidad de la situación o del tipo de relación interpersonal (de mayor respeto o más familiaridad). En esta lengua, esta distinción se tiene que deducir por el contexto lingüístico y por los aspectos paralingüísticos.

Para trabajar desde la pragmática y de forma integrada las formas de tratamiento personales, se puede plantear un juego de rol en el que una serie de personajes se encuentren en un acto social (por ejemplo, la inauguración de una exposición). El profesor o el conjunto de la clase debe definir los parámetros básicos de los distintos roles, incluyendo, entre otros, con la edad, la lengua, el grado de familiaridad o amistad, el grado de formalidad de la situación, etc.

En esta actividad van a entrar en juego varias combinaciones de parámetros que van a afectar a la forma de tratamiento personal. Por ejemplo:

1. Dos personas mayores, catalanohablantes, que apenas se conocen, van a tratarse de vostè o de vós.

2. Un joven y una persona mayor que hablan en inglés van a utilizar el pronombre you, aunque van a entrar en juego otras construcciones para marcar el tratamiento (el joven utilizará fórmulas como would you...?, más formal, mientras que la persona mayor se podría dirigir al joven con la forma más coloquial will you..? ).

3. Un chico joven colombiano va a hablar de vos a un chico de su edad, ya que en este país se trata de la forma de tratamiento coloquial.

La casuística se puede ampliar combinando personajes con distintas lenguas que interactúan entre ellos, otros ambientes, relaciones familiares, etc.

\section{Discusión y conclusiones}

En este trabajo hemos abordado tres dimensiones que afectan a la didáctica integrada de lenguas. En primer lugar, hemos analizado en qué puntos del currículum oficial se hace referencia a una competencia que implique una visión no sumativa, sino integrada, del conocimiento y uso de las lenguas. En segundo lugar, hemos apuntado las líneas básicas que fundamentan esta aproximación teórica, haciendo hincapié en las posibles transferencias entre lenguas y también en la necesidad de una organización legal y 
escolar que la haga posible. Y en tercer lugar, hemos propuesto una serie de actividades de diversos niveles gramaticales (fonética y fonología, morfología, sintaxis y semántica). Estas actividades están pensadas para trabajar de forma simultánea catalán, castellano e inglés en el aula. En general, todas las actividades provienen de situaciones reales o pseudoreales, para aumentar la motivación de los aprendices, y además están pensadas para potenciar su conciencia metalingüística.

Así pues, para poder articular una didáctica de lenguas, a nuestro entender, es necesario tener en cuenta estas tres dimensiones: la primera, que las directrices del currículum normativo alienten una aproximación integrada; la segunda, que haya una motivación a nivel del entorno escolar y que se aseguren las condiciones que han de permitir organizar este currículum en las tres lenguas; y la tercera, la preocupación por el diseño de actividades pensadas exclusivamente para utilizar las tres lenguas, que es el último eslabón sin el cual no se puede construir este tipo de andamiaje.

\section{BIBLIOGRAFÍA}

Chardenet, P. (2006). Produire des outils didactiques interlinguistiques, Rapport sur le développement des approches d'enseignement / apprentissage simultané de plusieurs langues (AUF). [Consultado el 23 de abril de 2013. http://www.3el.org/IMG/pdf/Rapport_approches_multilingues.pdf].

Consejo de Europa (2001). Marco común europeo de referencia para las lenguas: aprendizaje, enseñanza, evaluación. Madrid: Ministerio de Educación y Cultura.

Cummins, J. (1979). Cognitive / academic language proficiency, linguistic interdependence, the optimum age question and some other matters. Working Papers on Bilingualism 19, 121-129.

Currículum Educació Primària (2009). Barcelona: Servei de Comunicació, Distribució i Publicacions de la Generalitat de Catalunya.

Dolz, J., Gagnon, R. \& Mosquera, S. (2008). La didáctica de las lenguas: una disciplina en proceso de construcción. Didáctica. Lengua y Literatura 21, 117-141.

Ferrer, M. \& Rodríguez, C. (2010). Activitats discursives i gèneres de text com a marc d'integració de les llengües. In O. Guasch (coord.), El tractament integrat de les llengües. Barcelona: Graó.

Guasch, O. (2008). Reflexión interlingüística y enseñanza integrada de lenguas. Textos de Didáctica de la Lengua y de la Literatura 47, 20-32.

Hawkins, E. (1974). Modern Languages in the Curriculum. In Perren, G. (Ed.), The Space Between: English and Foreign Languages at School. Londres: CILT.

Jaeggli, O. \& Safir K. (1989). The null subject parameter. Dordrecht: Kluwer Academic Publishers.

Lasagabaster, D. (1998). The threshold hypothesis applied to three languages in contact at school. International Journal of Bilingual Education and Bilingualism 39, 119-133.

Marco de Referencia para los Enfoques Plurales de las Lenguas y de las Culturas (2008). [Consultado el 20 de abril de 2013. http://www.ecml.at/]. 
Millián, M. (2005). Parlar per “fer gramàtica”. Articles de Didàctica de la Llengua i de la Literatura 37, 11-30.

Noguerol, A. (2004). Ensenyar llengua en una societat multilingüe. Perspectiva escolar 290, 4-15.

Rodari, G. (1962). Favole al telefono. Torino : Guilio Einaudi.

Rodari, G. (1983). Cuentos por teléfono. Traducido por Ramón Prats de Alos-Moner. Barcelona : Juventud.

Rodari, G. (2006). Contes per telèfon. Traducido por Teresa Duran. Barcelona: Joventut.

Rodari, G. (2011). Contos por telefono. Traducido por Carlos Acevedo. Pontevedra: Kalandraka editora.

Roulet, E. (1980). Langue maternelle et langues secondes vers une pédagogie integrée. París : Crédif / Hatier.

Ruiz, U. (2008). La reflexión metalingüística desde varias lenguas. Textos de Didáctica de la Lengua y de la Literatura 47, 33-45.

Simard, C. (1997). Éléments de didactique du français langue première. Brusela : De Boeck.

\section{NOTAS}

1. Esta actividad y es productiva divertida, como demuestran neologismos como prepresident (hombre antes de ser presidente), trisuperable (una acción fácil que se puede superar tres veces) o redinar (comer dos veces) creados por niños (fuente: http://elbaguldeleslletres blogspot.com.es/search/label/prefixos\%2F\%20prefijos)

\section{RESÚMENES}

Este trabajo se centra en la didáctica integrada de lenguas en el contexto del Principado de Cataluña. En el currículo de Educación Primaria de Cataluña aparecen tres lenguas (el catalán, el castellano y una lengua extranjera, habitualmente el inglés) y también se hace referencia a una materia que se llama «Estructuras lingüísticas comunes», que se encarga del estudio de los aspectos lingüísticos compartidos entre las diversas lenguas. En este artículo presentamos una propuesta que incluye una serie de actividades pensadas para trabajar aspectos gramaticales de las tres lenguas de modo interrelacionado. Concretamente, se presenta una actividad para cada componente gramatical: fonética y fonología, morfología, sintaxis y pragmática. Así, con estas actividades se intenta dar cuenta de los requerimientos curriculares al tiempo que se utiliza la didáctica integrada de las lenguas, que es uno de los instrumentos adecuados para ayudar a alcanzar la competencia plurilingüe y multicultural que se pide desde el entorno comunitario.

This work focuses on the comprehensive teaching of languages in the context of the Principality of Catalonia. In the Primary School curriculum in Catalonia, there are three languages (Catalan, Spanish and a foreign language, normally English). And there is also a reference to an area called «Common linguistic structures», which deals with the study of the linguistic aspects shared by 
the different languages. In this article we put forward a proposal that includes a series of activities which have been designed to work grammatical aspects of the three languages in an interrelated fashion. More specifically, we present an activity for each grammatical component: phonetics and phonology, morphology, syntax and pragmatics. So with these activities we try to take into account the curriculum requirements while using the comprehensive teaching of the languages, which is one suitable instrument to help achieve the plurilingual and multicultural competence that is required by the common environment.

\section{ÍNDICE}

Palabras claves: actividades escolares, didáctica integrada de lenguas, fonética y fonología, morfología, pragmática, sintaxis

Keywords: comprehensive teaching of languages, curriculum, morphology, phonetics and phonology, pragmatics, school activities, syntax

\section{AUTORES}

\section{JORDI CICRES}

Profesor de Didáctica de la Lengua y de la Literatura, Grupo de Investigación en Lenguas y Aprendizaje, Instituto de Investigación Educativa, Universitat de Girona

\section{MARIA-DOLORS DE RIBOT}

Profesora de Didáctica de la Lengua y de la Literatura, Grupo de Investigación en Lenguas y Aprendizaje, Instituto de Investigación Educativa, Universitat de Girona

\section{SÍLVIA LLACH}

Profesora de Didáctica de la Lengua y de la Literatura, Grupo de Investigación en Lenguas y Aprendizaje, Instituto de Investigación Educativa, Universitat de Girona 